\title{
Genome-Wide Transcriptomic Analysis of $n$-Caproic Acid Production in Ruminococcaceae Bacterium CPB6 with Lactate Supplementation
}

\author{
Shaowen Lu' ${ }^{1}$ Hong Jin ${ }^{2}$, Yi Wang ${ }^{4}$, and Yong Tao ${ }^{1,3 *}$ \\ 'CAS Key Laboratory of Environmental and Applied Microbiology and Environmental Microbiology Key Laboratory \\ of Sichuan Province, Chengdu Institute of Biology, Chinese Academy of Sciences, Chengdu 610041, P.R. China \\ ${ }^{2}$ School of Basic Medical Science, Chengdu Medical College, Chengdu 610083, P.R. China \\ ${ }^{3}$ Faculty of Bioengineering, Sichuan University of Science and Engineering, Xueyuan Street 180\#, Huixing Rd. \\ Zigong 643000, P.R. China \\ ${ }^{4}$ Department of Biosystems Engineering, Auburn University, Auburn, Alabama, Alabama 36849, USA
}

$n$-Caproic acid (CA) is gaining increased attention due to its high value as a chemical feedstock. Ruminococcaceae bacterium strain CPB6 is an anaerobic mesophilic bacterium that is highly prolific in its ability to perform chain elongation of lactate to CA. However, little is known about the genome-wide transcriptional analysis of strain CPB6 for CA production triggered by the supplementation of exogenous lactate. In this study, cultivation of strain CPB6 was carried out in the absence and presence of lactate. Transcriptional profiles were analyzed using RNA-seq, and differentially expressed genes (DEGs) between the lactate-supplemented cells and control cells without lactate were analyzed. The results showed that lactate supplementation led to earlier CA p,roduction, and higher final CA titer and productivity. 295 genes were substrate and/or growth dependent, and these genes cover crucial functional categories. Specifically, 5 genes responsible for the reverse $\beta$-oxidation pathway, 11 genes encoding ATP-binding cassette (ABC) transporters, 6 genes encoding substrate-binding protein (SBP), and 4 genes encoding phosphotransferase system (PTS) transporters were strikingly upregulated in response to the addition of lactate. These genes would be candidates for future studies aiming at understanding the regulatory mechanism of lactate conversion into CA, as well as for the improvement of CA production in strain CPB6. The findings presented herein reveal unique insights into the biomolecular effect of lactate on CA production at the transcriptional level.

Received: July 6, 2021 Accepted: August 25, 2021

First published online: August 27, 2021

*Corresponding author Phone: 86-028-82890211 Fax: 86-028-82890211 E-mail: taoyong@cib.ac.cn

Supplementary data for this paper are available on-line only at http://jmb.or.kr.

pISSN 1017-7825 elSSN 1738-8872

Copyright $(\subset 2021$ by the authors. Licensee KMB. This article is an open access article distributed under the terms and condition of the Creative Commons Attribution (CC BY) license.
Keywords: $n$-Caproic acid, lactate, chain elongation, transcriptome, RNA-Seq

\section{Introduction}

The increasing demand for fuels and chemicals, and the scarcity of fossil resources necessitate the development of sustainable and innovative strategies for the industrial production. $n$-Caproic acid (CA) has recently gained considerable attention due to its high value as a chemical feedstock [1]. Organic residual streams (e.g., food waste and brewery wastewater) have great potential to be employed as feedstock for CA production [2,3]. Many studies show that the addition of ethanol during the acidification of wastes can promote chain elongation, and lead to higher volumetric production rate and a high CA selectivity [4,5]. Generally, biosynthesis of CA is achieved by some anaerobic microbes via the reverse $\beta$-oxidation pathway with ethanol as electron donor (ED) $[4,6]$, in which the oxidation of ethanol provides energy and acetyl-CoA for the chain elongation [7]. In addition to ethanol, many chemicals are explored as EDs for CA production, including hydrogen [8], methanol [9], propanol [10], and $D$ galactitol [11].

Recently, lactate is becoming a potential alternative to ethanol for the production of CA [12,13]. Lactate can be efficiently converted into CA by a Ruminococcaceae bacterium CPB6 [14]. The phylogenic analysis based on 16S rRNA sequences and the whole genome show that strain CPB6 might belong to a new clade (genus) of the family Ruminococcaceae, it is thus tentatively christened with the name Ruminococcaceae bacterium CPB6 [14]. Strain CPB6 can produce CA (C6) from lactate (as ED) with C2-C4 carboxylic acids as electron acceptors (EAs), or heptoic acid (C7) from lactate with C3-C5 carboxylic acids [15]. More recently, complete genomic sequencing and annotation show that strain CPB6 encodes most genes related to glycolysis and the reverse $\beta$-oxidation pathway 
[16]. However, to date, very little information is available on genome-wide transcriptomic analysis of strain CPB6 for CA production using lactate as $\mathrm{ED}$, which is essential to understand the effect of lactate on the metabolic pathway shift for CA production at the molecular level, and thus elucidate proper strategies for further strain improvement.

RNA-sequencing (RNA-Seq) is a powerful technique to investigate entire transcriptomes, and identify specific genes for the particular interesting metabolic pathways $[17,18]$. In this study, RNA-Seq of the transcriptome of strain CPB6 was carried out to investigate the effect of lactate supplementation on gene expression, as well as to identify key genes related to CA production. These candidate genes are likely to be valuable for the metabolic engineering in the future to further improve the ability of strain CPB6 to convert lactate into CA.

\section{Materials and Methods}

\section{Microorganisms, Media and Fermentation Experiment}

Ruminococcaceae bacterium CPB6 (GDMCC No.60133) is a spore-forming, obligate anaerobic bacterium that can produce CA from lactate [14]. Strain CPB6 was routinely cultured at $37^{\circ} \mathrm{C}$ anaerobically in a modified tryptone-glucose-yeast extract (mTGY) medium containing the following compounds ( $\mathrm{pH} 6.0$ ): $5.0 \mathrm{~g} / \mathrm{l}$ tryptone, $2.0 \mathrm{~g} / \mathrm{l}$ glucose, $3.5 \mathrm{~g} / \mathrm{l}$ sodium acetate, $0.41 \mathrm{~g} / \mathrm{l} \mathrm{K} \mathrm{HPO}_{4} \cdot 3 \mathrm{H}_{2} \mathrm{O}, 0.23 \mathrm{~g} / 1 \mathrm{KH}_{2} \mathrm{PO}_{4}, 0.25 \mathrm{~g} / \mathrm{l} \mathrm{NH}_{4} \mathrm{Cl}, 0.20 \mathrm{~g} / \mathrm{l}$ $\mathrm{MgSO}_{4} \cdot 7 \mathrm{H}_{2} \mathrm{O}, 2.5 \mathrm{~g} / \mathrm{l} \mathrm{NaHCO}, 0.50 \mathrm{~g} / \mathrm{l} \mathrm{L}$-cysteine, $0.25 \mathrm{~g} / \mathrm{l} \mathrm{Na} \mathrm{S}_{2} \cdot 9 \mathrm{H}_{2} \mathrm{O}, 0.0005 \mathrm{~g} / \mathrm{l}$ resazurin, and $1 \mathrm{ml}$ of trace element solution SL-10 and $1 \mathrm{ml}$ of vitamin solution [13]. The suspension of activated strain CPB6 was inoculated with a $5 \%$ ratio into the same medium as described above, and incubated for $12 \mathrm{~h}$ until the optical density at $600 \mathrm{~nm}\left(\mathrm{OD}_{600}\right)$ of the culture reached $0.8-1.0$. Then the culture would be used as the seed inoculum $(5 \% \mathrm{ratio}, \mathrm{v} / \mathrm{v})$ for batch experiments. To investigate the effect of lactate on cell growth and CA production, $5 \mathrm{~g} / \mathrm{l}$ sodium lactate was supplemented into the mTGY liquid medium (i.e., mTGYL). Batch experiments were performed in $250 \mathrm{ml}$ serum bottles containing $100 \mathrm{ml}$ of mTGY or mTGYL media. The headspace of the bottle was filled with highly pure $\mathrm{N}_{2}$. Each fermentation was performed in triplicate. The fermentation was carried out at $37^{\circ} \mathrm{C}$ in an E500 anaerobic workstation (Gene Science, USA) under $\mathrm{N}_{2}: \mathrm{CO}_{2}: \mathrm{H}_{2}$ (volume ratio of 80:10:10) atmosphere.

Samples were taken at specific times and processed for cell concentration determination and high-performance liquid chromatography (HPLC) analysis. Samples for RNA isolation were taken at the cell growth and stationary phases.

\section{Analytical Methods}

Culture growth was monitored by measuring the $\mathrm{OD}_{600}$ using a TU-1810 UV/Vis Spectrophotometer (Puxi Instrument Co. Ltd., China). Lactic acid, acetic acid, butyric acid, and caproic acid were quantified using an HPLC system (Agilent 1260 Infinity, USA) equipped with a differential refraction detector (RID) and a Agilent Hi-Plex $\mathrm{H}$ column $(300 \times 6.5 \mathrm{~mm})$ following the procedure as previously described [15].

RNA Isolation, Library Construction, and Sequencing

In preparation for RNA isolation, $10 \mathrm{ml}$ cell culture was harvested at each time point, and centrifuged at $8,000 \times g$ for $10 \mathrm{~min}$ at $4^{\circ} \mathrm{C}$. Cells were then frozen in liquid nitrogen prior to storage at $-80^{\circ} \mathrm{C}$. The RNA was extracted and purified using a RNA extraction kit (DP430, Tiangen Biotech, China) following the manufacturer's protocol. RNA quality and quantity were characterized using a NanoDrop2000 (NanoDrop Technologies, USA), agarose gel electrophoresis (RNA integrity detection) and Agilent 2100 (RIN value measurement). Only the RNA samples with high-quality ( $\geq 5 \mu \mathrm{g} ; \geq 200 \mathrm{ng} / \mu \mathrm{l}$; OD260/280=1.8 2.2; RIN $>6.0$ ) were used for the cDNA library construction and sequencing. Before library construction, rRNAs were removed with the Ribo-Zero rRNA Removal Kit (Epicentre, USA) following the manufacturer's protocol. The enriched mRNA was randomly fragmented into $200 \mathrm{bp}$ fragments by fragmentation buffer. The mRNA was then the first strand cDNA was synthesized using the random hexamer-primer with the mRNA fragment as the template. After synthesizing the second strand cDNA using DNA polymerase I and RNase $\mathrm{H}$, double-stranded cDNA was further end repaired, Atailed, and indexed adapters ligated. The final cDNA library was constructed using TruSeq RNA sample preparation Kit (Illumina Inc., USA), and then sequenced by Illumin Hiseq 4000 (Illumina Inc.) with $2 \times 150 \mathrm{bp}$.

Sequencing trimming and quality control methods are as follows: (1) Remove the Adapter sequence in reads; (2) The bases containing non-A, G, C and T at the 5 'end were removed by shear; (3) Trim the ends of reads with low sequencing quality (< Q20); (4) Reads containing $10 \% \mathrm{~N}$ were removed; (5) Remove Adapter and small segments with length less than $25 \mathrm{bp}$ after quality pruning.

\section{RNA-Seq Data Analysis}

Raw data were processed, and reads containing adapter and poly- $\mathrm{N}$ sequences and low-quality reads were removed using Sickle and SeqPrep to obtain clean data $[19,20]$. The trimmed reads in each sample were aligned to strain CPB6 genome (CP020705.1) using Bowtie2, and those that did not align uniquely to the genome were discarded using the default quality parameters [21]. Each base was assigned a value based on the number of mapped sequence coverage. Gene expression levels were defined using the number of transcripts per million (TPM), which is proportional to the quantity of cDNA fragments derived from the gene transcripts. The quantitative gene expression values between samples were identified by calculating the number of unambiguous tags for each gene and then normalizing this to TPM, which was calculated following the method reported by Parto et al. [22]. The gene expression results were visualized as a heat-map plot using ggplot 2 package. The general changes in gene expression among different treatments were evaluated by permutational multivariate analysis of 
variance using the function Adonis in the R vegan package. Gene annotation was performed based on the Kyoto Encyclopedia of Genes and Genomes (KEGG) database (http://www.genome.jp/kegg/).

\section{Reverse Transcription-Quantitative PCR (RT-qPCR)}

In order to validate the results of the RNA-Seq analysis, 5 candidate reference genes were selected for RT-qPCR confirmation. Primers used are listed in Supporting Information Table S3. Total RNA was extracted from three sets of independent cultures grown on cultures with or without lactate supplementation, and then converted to cDNA by random priming, using the Maxima Reverse Transcriptase (Thermo Scientific). PCR reactions were run in triplicate using procedure as follows: initial denaturation $\left(3 \mathrm{~min}\right.$ at $\left.95^{\circ} \mathrm{C}\right)$, followed by 45 cycles of denaturation $\left(5 \mathrm{~s}\right.$ at $95^{\circ} \mathrm{C}$ ), annealing and elongation $\left(30 \mathrm{~s}\right.$ at $\left.60^{\circ} \mathrm{C}\right)$. The transcription level of genes was determined according to the $2^{-(\Delta \Delta \mathrm{Ct})}$ method, using $16 \mathrm{~S}$ rRNA as a reference gene for the normalization of gene expression levels [23].

\section{Statistical Analysis}

Significant differences of the gene expression between the culture with lactate supplementation and the control were determined using ANOVA in R software (version 3.5.2). TPM values were first transformed to log10-scale. The $\log 10$-transformed TPM values were then properly centered for better representation of the data using the heatmap plots. Fold changes (FCs) as the ratio of the TPM values were calculated following the method reported by Love et al. [24], and were used to compare the differentially expressed genes (DEGs) between the culture from fermentation with lactate supplementation and the control.

\section{RNA-Seq Data}

The RNA-Seq sequencing data have been deposited in the NCBI Sequence Read Archive (SRA) under the accession number PRJNA564589

\section{Results}

\section{Cell Growth and the Production of CA}

As shown in Fig. 1A, cells took approximately $18 \mathrm{~h}$ to grow to the stationary phase. Although the maximum $\mathrm{OD}_{600}$ of the lactate-supplemented cultures was slightly higher than that of control cultures without lactate at the stationary phase (1.25 vs 1.16 ), both cultures showed similar growth kinetics. The lactate was completely consumed in the lactate supplemented culture after $21 \mathrm{~h}$ of cultivation. Moreover, no lactate was detected throughout the control group. CA production was started to be observed in the lactate-supplemented cultures after $6 \mathrm{~h}$ of cultivation, and the CA titer continued to increase and reached 1,717.2 mg/l at $21 \mathrm{~h}$ (Fig. 1B), while CA was not detected in control cells until $15 \mathrm{~h}$ of cultivation, and the CA titer of which only reached $618 \mathrm{mg} / \mathrm{l}$ at $21 \mathrm{~h}$ (Fig. 1C). These results suggest that lactate supplementation had little effect on the cell growth, but led to earlier initiation for CA production ( $6 \mathrm{vs} 15 \mathrm{~h}$ ), higher final CA titer (1,717 vs $618 \mathrm{mg} / \mathrm{l}$ ), and higher CA productivity (81.8 vs $29.4 \mathrm{mg} / \mathrm{lh}$ ).

RNA-Seq Statistics

Samples were taken for RNA-Seq analysis from both growth $(12 \mathrm{~h})$ and stationary $(18 \mathrm{~h})$ phases for the lactate-
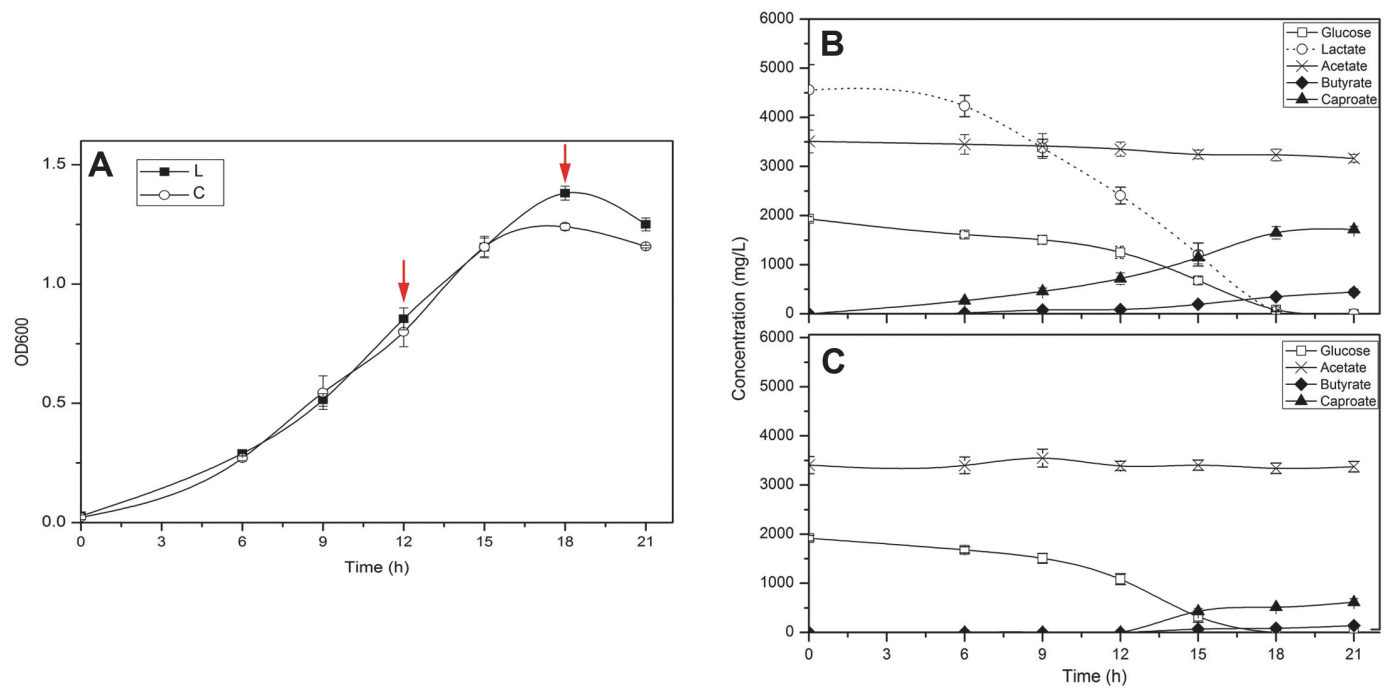

Fig. 1. Fermentation kinetics of Ruminococcaceae bacterium CPB6. (A) Cell growth profiles. Time points for taking samples subjected to RNA-Seq are indicated with red vertical arrows. L: fermentation with lactate supplementation; C: control fermentation without lactate supplementation; (B) Sugar consumption and metabolites production during the fermentation with the supplementation of lactate; (C) Sugar consumption and metabolites production during the control fermentation. Values represent the mean of the biological triplicates and error bars represent the standard deviations. 
Table 1. Summary of RNA-Seq sequencing and data analysis results.

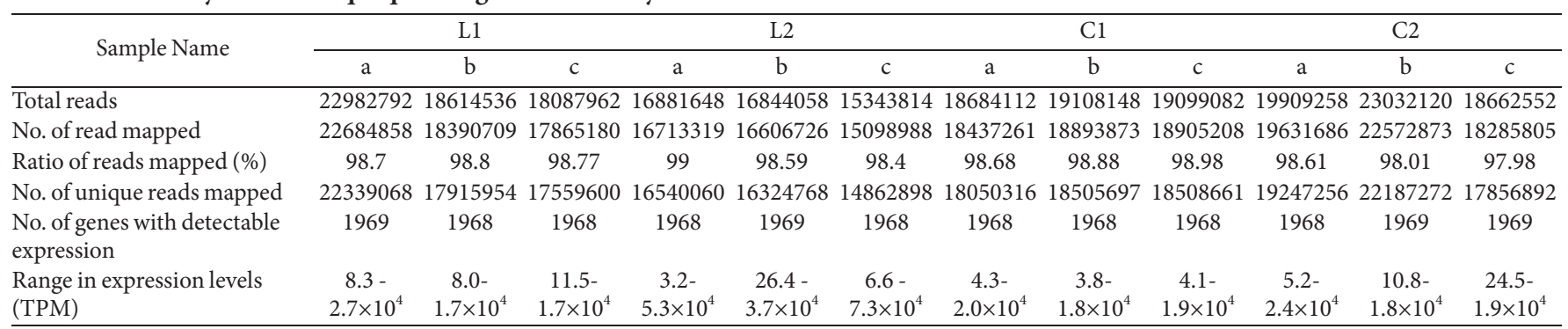

L1: cell culture with lactate supplementation from the growth phase;

L2: cell culture with lactate supplementation from the stationary phase;

$\mathrm{C} 1$ : Control culture without lactate supplementation from the growth phase;

$\mathrm{C} 2$ : Control culture without lactate supplementation from the stationary phase.

a and $c$ represented the biological triplicate samples.

supplemented cultures and control cultures. For each culture, independent biological triplicates (a, b, and c) were included (Table 1). Therefore, a total of twelve samples were taken for cDNA libraries construction and sequencing on the Illumina HiSeq 4000 (Illumina). The number of raw reads generated from the sequencing for each library was from 15.7 to 23.5 million (Table S1). A total of $224 \mathrm{Mb}$ sequence reads from $12 \mathrm{cDNA}$ libraries were mapped to strain CPB6 genome. Only those reads that mapped unambiguously to strain CPB6 genome were used for further analysis.

Overall, out of the reads derived from all samples, 15.1 to 22.7 million reads were unambiguously mapped to strain CPB6 genome, and over 98\% reads were mapped (Table 1). A total of 1968/1969 out of 2045 protein-coding genes had detectable expression in all cells, covering 96\% of strain CPB6 genome. This result indicated that the RNA-Seq analysis achieved comprehensive coverage of strain CPB6 transcriptome. The transcription levels (the number of transcripts per million, TPM) of most active protein-coding genes were in the range of $3.2 \times 10^{4}-$ $7.3 \times 10^{4}$.

As illustrated in Fig. 2, the gene expression could be classified into four levels: low (TPM $<30)$, moderate (TPM: 30-150), high (TPM: 150-1000), and very high (TPM > 1000). The number of genes at some specific expression levels was significantly different for the two cultures. For the growth phase, there were slightly more genes in the moderate, high and very high expression level in the lactate-treated cells than in control cells, but lowly expressed genes were significantly decreased. While for the stationary phase, the lactate-treated cells had more genes in the moderate expression level, but fewer genes in the high and very high expression level.

\section{Functional Annotation and Classification}

In the transcriptome of strain CPB6, a total of 1122 expressed genes were allocated into three primary Gene Ontology (GO) categories (Fig. 3), including the category of biological process (601 genes), cellular component (524 genes), and molecular function (916 genes). In each category, the genes were further assigned into 28 functional groups, such as metabolic process (478 genes), cellular process (440 genes), cell part (307 genes),

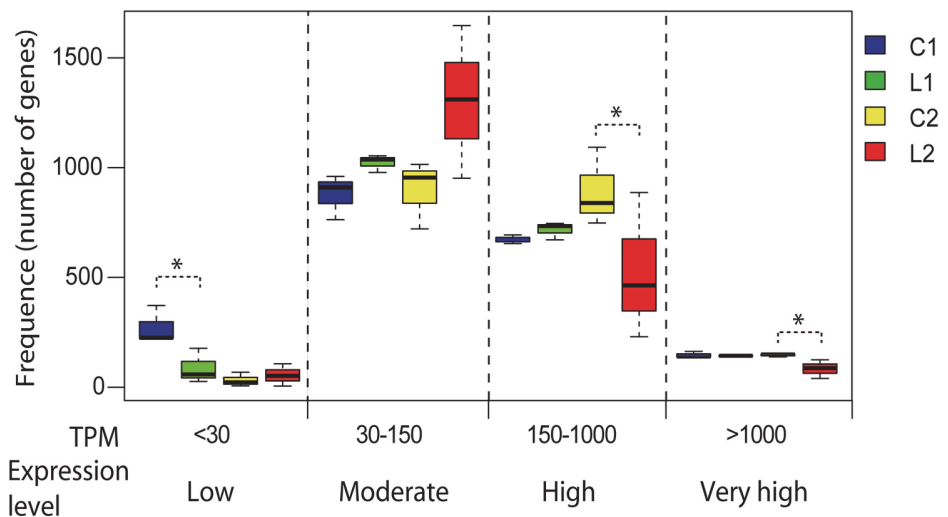

Fig. 2. Frequency histogram of transcripts from the RNA-Seq results. L: the lactate supplemented cells; C: control cells without lactate supplementation; Number 1 and 2 represented the growth phase and stationary phase, respectively. The diagram shows the distribution of the number of genes expressed at different transcripts per million (TPM) levels. The percentage value above each bar indicates the genes at the specific expression level accounting for the proportion of the total number of genes. The '*' mark indicates that significantly different frequencies (i.e., numbers of genes) were observed between the two RNA-Seq data sets from the lactate-supplemented fermentation (L) vs. the control (C), respectively. 


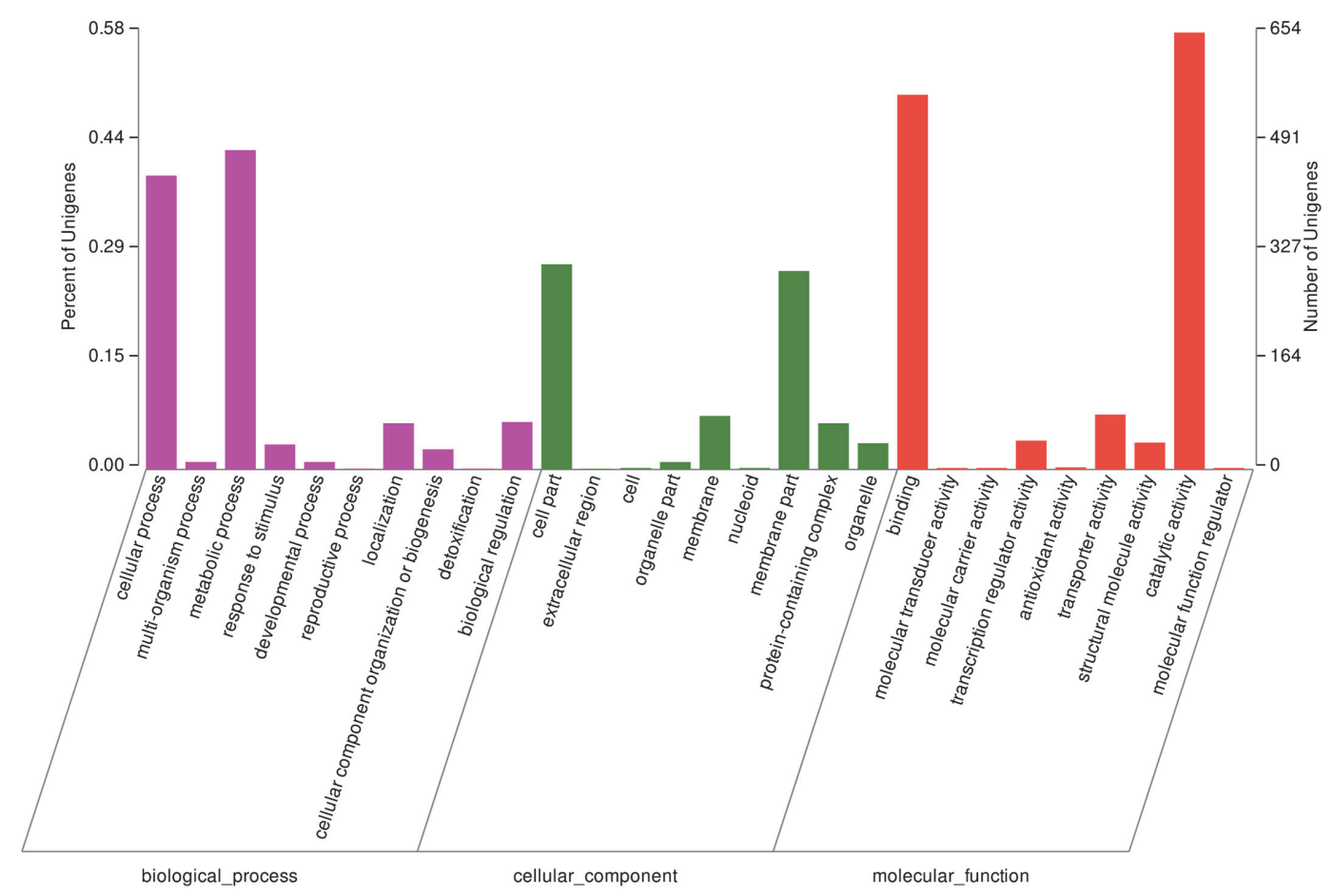

Fig. 3. Annotation of genes using Gene Ontology (GO) in the transcriptome of strain CPB6. Left axis: the proportion of genes falling into each $\mathrm{GO}$ category; right axis: the number of genes falling into each $\mathrm{GO}$ category.

membrane part (297 genes), catalytic activity (654 genes), binding (561genes), and etc. The analysis of the genes based on the KEGG annotation identified a total of 1046 unigenes allocated into six primary KEGG categories including 35 subcategories (Fig. S1). The analysis based on the Clusters of Orthologous Groups (COGs) showed that 1785 unigenes were allocated to four primary COG categories containing 20 COG functional clusters (Fig. S2).

\section{DEGs Affected by Lactate Supplementation}

The correct identification of DEGs between specific conditions is a key in understanding phenotypic variation of organisms under environmental stress. As shown in Table 2 , only 34 DEGs $(\mathrm{FC} \geq 2$ or $\leq 0.5$ with $p$-value $<0.05$ ) were found in the lactate-supplemented cells compared to control cells at the growth phase, of which 15 genes were upregulated, and 19 genes were downregulated. At the stationary phase, a total of 245 DEGs were identified in both cultures, of which 123 genes were significantly upregulated and 122 genes were downregulated (Table S2). These results demonstrated that the addition of lactate led to differences in gene expression during different growth phases.

The COG distribution of DEGs is illustrated in Fig. S3. It revealed potential genes, processes and pathways that

A

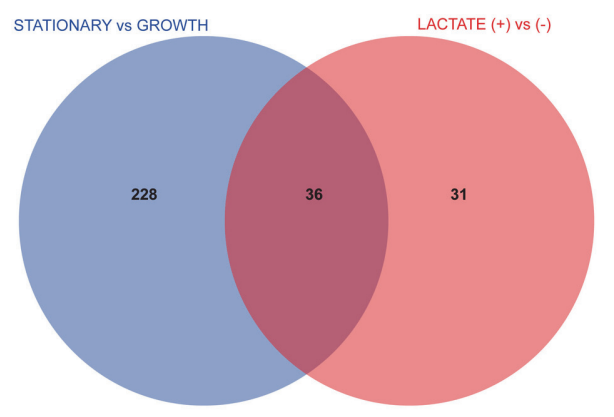

B

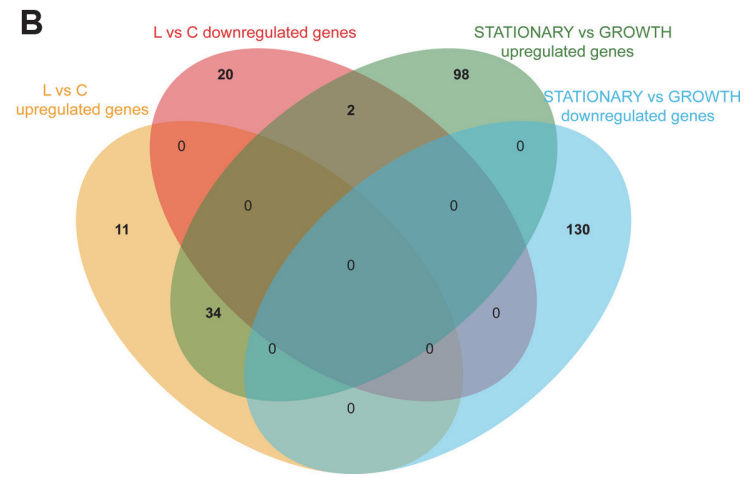

Fig. 4. Venn diagram of the numbers of differentially expressed genes (DEGs) trigger by substrate type (plus/ minus lactate) vs growth stage (stationary phase vs growth phase) (A), the numbers of DEGs trigger by substrate type vs growth stage (B). The overlap of circles was defined as genes affected by both substrate type and growth stage. 
Table 2. The differentially expressed genes in culture with/without lactate supplementation during the growth phase.

\begin{tabular}{|c|c|c|c|c|c|c|c|}
\hline \multirow{2}{*}{ No. } & \multirow[b]{2}{*}{ Gene_ID } & \multirow{2}{*}{$\begin{array}{l}\text { Gene } \\
\text { name }\end{array}$} & \multirow{2}{*}{ Gene description } & \multicolumn{2}{|c|}{ TPM } & \multirow{2}{*}{$\begin{array}{l}\text { FC } \\
(\mathrm{L} 1 / \\
\mathrm{C} 1)\end{array}$} & \multirow{2}{*}{$P$-value } \\
\hline & & & & $\mathrm{C} 1$ & L1 & & \\
\hline \multicolumn{8}{|c|}{15 upregulated genes $(\mathrm{FC} \geq 2.0)$; all statistically significant $(P<0.05)$} \\
\hline 1 & B6259_RS06365 & AtoB & acetyl-CoA C-acetyltransferase & 1224 & 5204 & 3.45 & 7.9E-39 \\
\hline 2 & B6259_RS06360 & Crt & enoyl-CoA hydratase & 795 & 3434 & 3.46 & $2.4 \mathrm{E}-33$ \\
\hline 3 & B6259_RS06355 & Hbd & 3-hydroxybutyryl-CoA dehydrogenase & 1418 & 6306 & 3.49 & $2.3 \mathrm{E}-27$ \\
\hline 4 & B6259_RS07830 & Pta & phosphate acetyltransferase & 271 & 666 & 2.09 & $4.3 \mathrm{E}-24$ \\
\hline 5 & B6259_RS00440 & - & methionine $\mathrm{ABC}$ transporter ATP-binding protein & 51 & 504 & 5.25 & $6.2 \mathrm{E}-18$ \\
\hline 6 & B6259_RS00450 & - & metal $\mathrm{ABC}$ transporter substrate-binding protein & 30 & 699 & 5.69 & $5.9 \mathrm{E}-15$ \\
\hline 7 & B6259_RS00445 & - & $\mathrm{ABC}$ transporter permease & 27 & 446 & 5.17 & $6.9 \mathrm{E}-14$ \\
\hline 8 & B6259_RS08190 & CysK & cysteine synthase A & 390 & 7426 & 4.07 & $6.4 \mathrm{E}-10$ \\
\hline 9 & B6259_RS08440 & - & unknown function & 1048 & 3598 & 2.33 & $5.2 \mathrm{E}-06$ \\
\hline 10 & B6259_RS06010 & - & hypothetical protein & 21 & 89 & 2.52 & 8.1E-06 \\
\hline 11 & B6259_RS07140 & - & hypothetical protein & 154 & 470 & 2.17 & $3.0 \mathrm{E}-05$ \\
\hline 12 & B6259_RS01720 & CadA & cadmium-translocating P-type ATPase & 22 & 66 & 2.16 & $3.9 \mathrm{E}-05$ \\
\hline 13 & B6259_RS06870 & - & Hsp20/alpha crystallin family protein & 315 & 1102 & 2.21 & $1.6 \mathrm{E}-04$ \\
\hline 14 & B6259_RS00455 & PepT & peptidase T & 37 & 576 & 2.26 & $2.0 \mathrm{E}-04$ \\
\hline 15 & B6259_RS02585 & Bdh & butanol dehydrogenase & 82 & 242 & 2.04 & 3.1E-04 \\
\hline \multicolumn{8}{|c|}{19 downregulated genes $(\mathrm{FC} \leq 0.5)$; all statistically significant $(P<0.05)$} \\
\hline 1 & B6259_RS08515 & - & peptide $\mathrm{ABC}$ transporter substrate-binding protein & 98 & 53 & 0.48 & $1.7 \mathrm{E}-23$ \\
\hline 2 & B6259_RS09280 & - & PTS glucose transporter subunit IIA & 1200 & 484 & 0.37 & $5.5 \mathrm{E}-23$ \\
\hline 3 & B6259_RS09735 & IlvH & acetolactate synthase small subunit & 564 & 302 & 0.48 & $9.4 \mathrm{E}-19$ \\
\hline 4 & B6259_RS06995 & - & hypothetical protein & 276 & 43 & 0.20 & $2.7 \mathrm{E}-18$ \\
\hline 5 & B6259_RS08565 & - & hypothetical protein & 143 & 79 & 0.50 & $2.3 \mathrm{E}-13$ \\
\hline 6 & B6259_RS07000 & - & sugar $\mathrm{ABC}$ transporter permease & 113 & 31 & 0.30 & $9.2 \mathrm{E}-13$ \\
\hline 7 & B6259_RS01525 & - & unknown function & 2683 & 1010 & 0.37 & $8.4 \mathrm{E}-12$ \\
\hline 8 & B6259_RS03200 & - & unknown function & 2683 & 1010 & 0.37 & $8.4 \mathrm{E}-12$ \\
\hline 9 & B6259_RS07010 & Tag & glycosylase & 144 & 46 & 0.34 & $9.9 \mathrm{E}-11$ \\
\hline 10 & B6259_RS07005 & - & carbohydrate $\mathrm{ABC}$ transporter permease & 90 & 33 & 0.37 & $1.1 \mathrm{E}-09$ \\
\hline 11 & B6259_RS01865 & - & DUF2520 domain-containing protein & 260 & 85 & 0.36 & $6.7 \mathrm{E}-09$ \\
\hline 12 & B6259_RS01880 & PanD & aspartate 1-decarboxylase & 444 & 156 & 0.37 & $9.5 \mathrm{E}-09$ \\
\hline 13 & B6259_RS01870 & PanB & 3-methyl-2-oxobutanoate hydroxymethyltransferase & 314 & 105 & 0.37 & $1.1 \mathrm{E}-08$ \\
\hline 14 & B6259_RS01875 & Panc & pantoate-beta-alanine ligase & 350 & 115 & 0.37 & $1.2 \mathrm{E}-08$ \\
\hline 15 & B6259_RS01760 & - & hypothetical protein & 820 & 369 & 0.44 & $8.9 \mathrm{E}-08$ \\
\hline 16 & B6259_RS02315 & - & basic amino acid $\mathrm{ABC}$ transporter substrate-binding protein & 147 & 79 & 0.50 & $1.8 \mathrm{E}-07$ \\
\hline 17 & B6259_RS00100 & FruK & 1-phosphofructokinase & 1256 & 276 & 0.35 & $1.7 \mathrm{E}-06$ \\
\hline 18 & B6259_RS00095 & - & PTS fructose transporter subunit IIC & 1273 & 372 & 0.37 & $1.8 \mathrm{E}-06$ \\
\hline 19 & B6259_RS00105 & - & DeoR/GlpR transcriptional regulator & 1304 & 278 & 0.36 & $3.6 \mathrm{E}-06$ \\
\hline
\end{tabular}

L1: lactate-supplemented cells at growth phase

C1: no-lactate-supplemented cells (control) at growth phase

may participate in the utilization of lactate and CA production. Cluster analysis of the DEGs between the lactatesupplemented cells and control cells is showed in Fig. S4. Obviously, more DEGs was observed in the stationary phase (L2 vs C2) than in the growth phase (L1 vs C1).

As shown in Fig. 4, a total of 295 DEGs in expression pattern were substrate and/or growth dependent, of which 31 genes were substrate (lactate) dependent, 228 genes were growth dependent, and 36 genes were substrategrowth dependent (Fig. 4A). Specifically, 11 and 20 lactate-dependent genes were significantly upregulated and downregulated, as well as 98 and 130 growth-dependent genes were significantly upregulated and downregulated, respectively (Fig. 4B). It was suggested that the differences in gene expression are stronger for stationary phase vs growth phase than for plus/minus lactate. Similar results was observed for C. thermocellum, in which growth rate had stronger effects on gene expression than substrate type [25].

\section{Expression of Glycolysis Genes}

An overview of the metabolic pathway in strain CPB6, and the expression levels of genes involved in key metabolic processes with their fold change (FC) were shown in Fig. 5 and Table 3. Most glycolytic genes were expressed at a relatively high level (TPM $>150)$ between the lactate-supplemented cells and control cells, but there was no significant difference $(p>0.05)$ between them at the growth phase. Three glycolytic genes exhibited different expression patterns at the stationary phase. Gene encoding phosphofructokinase (Pfk, B6259_RS06095) was significantly downregulated $(p<0.05)$, while genes encoding glucose-1-phosphate adenylyltransferase (GlgC, B6259_RS09035) and 1, 4-alpha-glucan branching enzyme (GlgB, B6259_RS09040) were upregulated by 4.58 and 3.42 -fold $(p<0.05)$ in the lactate-supplemented cells compared with control cells, respectively. GlgB and GlgC are typically associated with glycogen synthesis, why expression of these genes be affected by lactate 


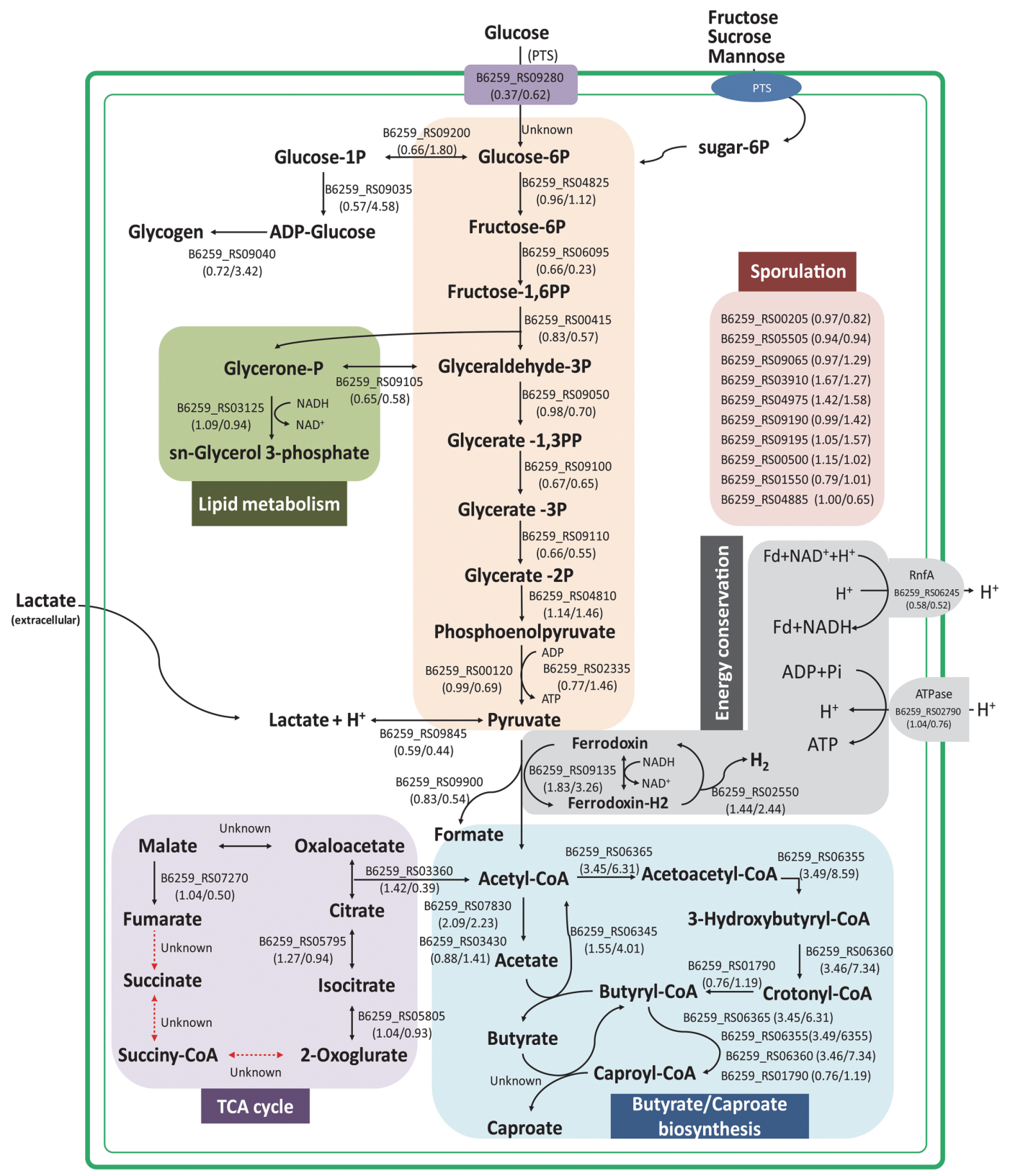

Fig. 5. The overview of the central metabolic pathway in strain CPB6 with fold changes (FCs) of the expression of genes. The number in parentheses represents the FC of TPM between the lactate supplemented cells vs. control cells; the first and the second numbers in the same parentheses represent the gene expression FC in the growth and stationary phases, respectively. Black solid lines symbolize enzymatic reactions. Red dashed lines mark enzymatic reactions for which corresponding enzymes are probably not encoded in strain CPB6.

supplementation remains unclear. Overall, the addition of lactate has little impact on the expression of glycolytic genes.

Two ldh genes (B6259_RS09845 and RS06770), encoding L-lactate dehydrogenase and D-lactate dehydrogenase, were detected in strain CPB6 transcriptome, respectively. The two ldh genes were expressed at low levels in the lactate-supplemented cells and control cells (Table 3), and there was no significant difference in the expression level between the two groups. The gene encoding pyruvate: ferredoxin (flavodoxin) oxidoreductase (Pfor, B6259_RS09135) was upregulated by 1.83 - and 3.26-fold $(p<0.05)$ in the lactate supplemented cells than in control cells during the growth and stationary phases, respectively.

\section{Expression of Butyrate- and CA-Producing Genes}

The enzymes involved in the butyrate formation include acetyl-CoA acetyltransferase (AtoB), 3-hydroxybutyrylCoA dehydrogenase (Hbd), enoyl-CoA hydratase (Crt), NAD-dependent butyryl-CoA dehydrogenase/Electron 
Table 3. The differentially expressed genes within the important metabolic pathways in culture with/without lactate supplementation.

\begin{tabular}{|c|c|c|c|c|c|c|c|}
\hline \multirow[t]{2}{*}{ Functional description } & \multirow[t]{2}{*}{ Gene_ID } & \multicolumn{2}{|c|}{$\begin{array}{c}\text { TPM of genes } \\
\text { from culture with } \\
\text { lactate } \\
\text { supplementation }\end{array}$} & \multicolumn{2}{|c|}{$\begin{array}{l}\text { TPM of genes } \\
\text { from the } \\
\text { Control }^{\text {a }}\end{array}$} & \multicolumn{2}{|c|}{$\begin{array}{l}\text { RNA relative } \\
\text { fold change } \\
\text { (Treatment/ } \\
\text { Control) }\end{array}$} \\
\hline & & $12 \mathrm{~h}$ & $18 \mathrm{~h}$ & $12 \mathrm{~h}$ & $18 \mathrm{~h}$ & $12 \mathrm{~h}$ & $18 \mathrm{~h}$ \\
\hline \multicolumn{8}{|l|}{ Glycolysis } \\
\hline PTS-Glc-EIIA, PTS glucose transporter subunit IIA & B6259_RS09280 & 484 & 260 & 1200 & 517 & $0.37^{\mathrm{c}}$ & 0.62 \\
\hline GlgC, glucose-1-phosphate adenylyltransferase & B6259_RS09035 & 153 & 1323 & 236 & 241 & 0.57 & $4.58^{b}$ \\
\hline GlgB, 1,4-alpha-glucan branching enzyme & B6259_RS09040 & 194 & 745 & 236 & 201 & 0.72 & $3.42^{b}$ \\
\hline sugar phosphate isomerase/epimerase & B6259_RS06500 & 181 & 175 & 150 & 233 & 1.05 & 0.88 \\
\hline Pgm, phosphoglucomutase & B6259_RS09200 & 95 & 189 & 127 & 113 & 0.66 & 1.80 \\
\hline Gpi, glucose-6-phosphate isomerase & B6259_RS04825 & 2015 & 1789 & 1833 & 1818 & 0.96 & 1.12 \\
\hline Pfk, phosphofructokinase & B6259_RS06095 & 426 & 97 & 580 & 516 & 0.66 & $0.23^{\mathrm{c}}$ \\
\hline Aldo, fructose-bisphosphate aldolase & B6259_RS00415 & 749 & 402 & 800 & 891 & 0.83 & 0.57 \\
\hline Tpi, triose-phosphate isomerase & B6259_RS09105 & 224 & 229 & 315 & 493 & 0.65 & 0.58 \\
\hline GapA, glyceraldehyde phosphate dehydrogenase & B6259_RS09050 & 5322 & 4284 & 4790 & 7732 & 0.98 & 0.70 \\
\hline Pgk, phosphoglycerate kinase & B6259_RS09100 & 523 & 524 & 705 & 1029 & 0.67 & 0.65 \\
\hline $\begin{array}{l}\text { GpmI, 2,3-bisphosphoglycerate-independent } \\
\text { phosphoglycerate mutase }\end{array}$ & B6259_RS09110 & 203 & 200 & 284 & 469 & 0.66 & 0.55 \\
\hline Eno, phosphopyruvate hydratase & B6259_RS04810 & 41 & 65 & 30 & 52 & 1.14 & 1.46 \\
\hline $\mathrm{PK}$, pyruvate kinase & B6259_RS02335 & 254 & 102 & 293 & 228 & 0.77 & 1.46 \\
\hline \multicolumn{8}{|l|}{ Central pyruvate metabolism } \\
\hline PpdK, pyruvate phosphate dikinase & B6259_RS00120 & 1301 & 823 & 1163 & 1535 & 0.99 & 0.69 \\
\hline Pfor, pyruvate: ferredoxin (flavodoxin) oxidoreductase & B6259_RS09135 & 4329 & 4382 & 2044 & 1225 & 1.83 & $3.26^{b}$ \\
\hline Pck, phosphoenolpyruvate carboxykinase & B6259_RS09255 & 368 & 159 & 554 & 1031 & 0.62 & $0.23^{\mathrm{c}}$ \\
\hline PflD, formate C-acetyltransferase & B6259_RS09900 & 98 & 188 & 107 & 471 & 0.83 & 0.54 \\
\hline Adh, alcohol dehydrogenase & B6259_RS03100 & 200 & 116 & 163 & 159 & 1.07 & 0.84 \\
\hline \multicolumn{8}{|l|}{ Incomplete TCA cycle } \\
\hline Cs, citrate synthase, citrate lyase & B6259_RS03360 & 936 & 187 & 543 & 642 & 1.42 & $0.39^{\mathrm{c}}$ \\
\hline Aco, aconitate hydratase & B6259_RS05795 & 227 & 162 & 153 & 201 & 1.27 & 0.94 \\
\hline Idh, isocitrate dehydrogenase & B6259_RS05805 & 237 & 232 & 197 & 291 & 1.04 & 0.93 \\
\hline Fum, fumarate hydratase & B6259_RS07270 & 310 & 186 & 260 & 437 & 1.04 & $0.49^{\mathrm{c}}$ \\
\hline Pck, phosphoenolpyruvate carboxykinase & B6259_RS09255 & 368 & 159 & 554 & 1031 & 0.62 & $0.23^{c}$ \\
\hline \multicolumn{8}{|l|}{ Hydrogen production } \\
\hline HydE, $[\mathrm{FeFe}]$ hydrogenase $\mathrm{H}$-cluster & B6259_RS02550 & 113 & 73 & 174 & 44 & 1.44 & $2.24^{\mathrm{b}}$ \\
\hline HydF, [FeFe] hydrogenase $\mathrm{H}$-cluster & B6259_RS09690 & 67 & 40 & 50 & 24 & 1.43 & 1.17 \\
\hline \multicolumn{8}{|l|}{ Lactate fermentation pathway } \\
\hline D-ldh, D-lactate dehydrogenase & B6259_RS06770 & 76 & 88 & 58 & 108 & 1.14 & 0.95 \\
\hline L-ldh, L-lactate dehydrogenase & B6259_RS09845 & 79 & 111 & 119 & 295 & 0.59 & $0.44^{\mathrm{c}}$ \\
\hline \multicolumn{8}{|l|}{ Acetate fermentation pathway } \\
\hline Pta, phosphate acetyltransferase & B6259_RS07830 & 666 & 697 & 271 & 321 & $2.09^{b}$ & $2.23^{b}$ \\
\hline Ack, acetate kinase & B6259_RS03430 & 290 & 297 & 288 & 233 & 0.88 & 1.41 \\
\hline \multicolumn{8}{|l|}{ The reverse $\beta$-oxidation pathway } \\
\hline AtoB, acetyl-CoA C-acetyltransferase & B6259_RS06365 & 5204 & 9909 & 1224 & 1077 & $3.45^{b}$ & $6.31^{b}$ \\
\hline Hbd, 3-hydroxybutyryl-CoA dehydrogenase & B6259_RS06355 & 6306 & 13975 & 1418 & 1022 & $3.49^{b}$ & $8.59^{b}$ \\
\hline Crt, enoyl-CoA hydratase & B6259_RS06360 & 3434 & 7348 & 795 & 647 & $3.46^{b}$ & $7.34^{\mathrm{b}}$ \\
\hline Bcd1, butyryl-CoA dehydrogenase & B6259_RS01790 & 3278 & 3104 & 3787 & 3014 & 0.76 & 1.19 \\
\hline Bcd2, butyryl-CoA dehydrogenase & B6259_RS02600 & 42 & 313 & 41 & 66 & 0.90 & $4.49^{b}$ \\
\hline EtfA, electron transfer flavoprotein subunit alpha & B6259_RS01785 & 2657 & 2968 & 3175 & 2572 & 0.73 & 1.31 \\
\hline EtfB, electron transfer flavoprotein subunit beta & B6259_RS01780 & 3996 & 4830 & 4357 & 4169 & 0.71 & 1.31 \\
\hline CoAT, butyryl-CoA: acetate CoA-transferase & B6259_RS06345 & 521 & 1497 & 283 & 330 & 1.55 & $4.01^{b}$ \\
\hline \multicolumn{8}{|l|}{ Fructose fermentation pathway } \\
\hline Ppf, 1-phosphofructokinase & B6259_RS00100 & 276 & 2174 & 1256 & 239 & $0.35^{\mathrm{c}}$ & $7.33^{b}$ \\
\hline \multicolumn{8}{|l|}{ Starch and sucrose metabolism } \\
\hline Pyg, glycogen phosphorylase & B6259_RS00300 & 90 & 163 & 121 & 103 & 0.66 & 1.71 \\
\hline MalQ, 4-alpha-glucanotransferase & B6259_RS07805 & 53 & 270 & 55 & 61 & 0.85 & $4.34^{b}$ \\
\hline Pgm, Phosphoglucomutase & B6259_RS09200 & 95 & 189 & 127 & 113 & 0.66 & 1.80 \\
\hline
\end{tabular}


Table 3. Continued.

\begin{tabular}{|c|c|c|c|c|c|c|c|}
\hline \multirow[t]{2}{*}{ Functional description } & \multirow[t]{2}{*}{ Gene_ID } & \multicolumn{2}{|c|}{$\begin{array}{c}\text { TPM of genes } \\
\text { from culture with } \\
\text { lactate } \\
\text { supplementation }^{\text {a }}\end{array}$} & \multicolumn{2}{|c|}{$\begin{array}{l}\text { TPM of genes } \\
\text { from the } \\
\text { Control }^{\mathrm{a}}\end{array}$} & \multicolumn{2}{|c|}{$\begin{array}{c}\text { RNA relative } \\
\text { fold change } \\
\text { (Treatment/ } \\
\text { Control) }\end{array}$} \\
\hline & & $12 \mathrm{~h}$ & $18 \mathrm{~h}$ & $12 \mathrm{~h}$ & $18 \mathrm{~h}$ & $12 \mathrm{~h}$ & $18 \mathrm{~h}$ \\
\hline \multicolumn{8}{|l|}{ Energy conservation } \\
\hline energy-coupling factor transporter ATPase & B6259_RS02790 & 141 & 104 & 117 & 159 & 1.04 & 0.76 \\
\hline electron transport complex protein RnfA & B6259_RS06245 & 230 & 162 & 357 & 362 & 0.58 & 0.52 \\
\hline \multicolumn{8}{|l|}{ Sporulation } \\
\hline stage 0 sporulation protein & B6259_RS00205 & 379 & 279 & 233 & 252 & 0.97 & 0.82 \\
\hline stage II sporulation protein D & B6259_RS09065 & 98 & 59 & 96 & 53 & 0.97 & 1.29 \\
\hline stage III sporulation protein $\mathrm{AD}$ & B6259_RS03910 & 126 & 54 & 87 & 26 & 1.67 & 1.27 \\
\hline stage IV sporulation protein A & B6259_RS04975 & 65 & 30 & 58 & 16 & 1.42 & 1.58 \\
\hline stage $\mathrm{V}$ sporulation protein $\mathrm{AC}$ & B6259_RS09190 & 89 & 46 & 77 & 40 & 0.99 & 1.42 \\
\hline stage $\mathrm{V}$ sporulation protein $\mathrm{AD}$ & B6259_RS09195 & 69 & 41 & 66 & 34 & 1.05 & 1.57 \\
\hline stage $\mathrm{V}$ sporulation protein $\mathrm{AE}$ & B6259_RS00500 & 292 & 226 & 200 & 167 & 1.15 & 1.02 \\
\hline sporulation transcription factor Spo0A & B6259_RS05505 & 127 & 115 & 83 & 106 & 0.94 & 0.94 \\
\hline sporulation transcriptional regulator SpoIIID & B6259_RS01550 & 213 & 188 & 140 & 207 & 0.79 & 1.01 \\
\hline sporulation protein YtfJ & B6259_RS04885 & 291 & 183 & 145 & 159 & 1.00 & 0.65 \\
\hline \multicolumn{8}{|l|}{ Transporter genes } \\
\hline $\mathrm{ABC}$ transporter permease & B6259_RS00445 & 446 & 274 & 27 & 235 & $5.17^{b}$ & 1.27 \\
\hline metal ABC transporter & B6259_RS00450 & 699 & 628 & 30 & 457 & $5.69^{b}$ & 1.52 \\
\hline $\mathrm{ABC}$ transporter permease & B6259_RS02670 & 296 & 130 & 441 & 387 & 0.60 & $0.40^{c}$ \\
\hline $\mathrm{ABC}$ transporter permease & B6259_RS02665 & 180 & 96 & 258 & 231 & 0.62 & $0.48^{c}$ \\
\hline carbohydrate $\mathrm{ABC}$ transporter permease & B6259_RS07005 & 33 & 124 & 90 & 41 & $0.37^{\mathrm{c}}$ & $3.51^{b}$ \\
\hline carbohydrate $\mathrm{ABC}$ transporter permease & B6259_RS07905 & 71 & 744 & 71 & 40 & 0.90 & $12.71^{\mathrm{b}}$ \\
\hline carbohydrate $\mathrm{ABC}$ transporter permease & B6259_RS07810 & 39 & 229 & 40 & 45 & 0.85 & $5.48^{\mathrm{b}}$ \\
\hline carbohydrate $\mathrm{ABC}$ transporter permease & B6259_RS02030 & 26 & 71 & 16 & 39 & 1.35 & $2.14^{b}$ \\
\hline sugar $\mathrm{ABC}$ transporter permease & B6259_RS07910 & 82 & 1175 & 88 & 50 & 0.86 & $14.74^{b}$ \\
\hline sugar $\mathrm{ABC}$ transporter permease & B6259_RS03335 & 39 & 401 & 26 & 61 & 1.30 & $5.61^{\mathrm{b}}$ \\
\hline sugar $\mathrm{ABC}$ transporter permease & B6259_RS07815 & 36 & 197 & 37 & 49 & 0.85 & $4.34^{\mathrm{b}}$ \\
\hline sugar $\mathrm{ABC}$ transporter permease & B6259_RS07000 & 31 & 135 & 113 & 38 & $0.30^{c}$ & $3.48^{b}$ \\
\hline iron $\mathrm{ABC}$ transporter permease & B6259_RS00320 & 53 & 1278 & 77 & 89 & 0.62 & $10.05^{b}$ \\
\hline $\mathrm{ABC}$ transporter ATP-binding protein & B6259_RS00440 & 504 & 277 & 51 & 239 & $5.25^{b}$ & 1.39 \\
\hline $\mathrm{ABC}$ transporter ATP-binding protein & B6259_RS00325 & 60 & 2032 & 94 & 100 & 0.58 & $11.14^{b}$ \\
\hline $\mathrm{ABC}$ transporter ATP-binding protein & B6259_RS08900 & 153 & 682 & 233 & 214 & 0.58 & $3.13^{\mathrm{b}}$ \\
\hline $\mathrm{ABC}$ transporter ATP-binding protein & B6259_RS07940 & 190 & 40 & 259 & 94 & 0.66 & 0.42 \\
\hline carbohydrate $\mathrm{ABC}$ transporter substrate-binding protein & B6259_RS07915 & 216 & 3434 & 203 & 103 & 0.93 & $14.51^{\mathrm{b}}$ \\
\hline maltose $\mathrm{ABC}$ transporter substrate-binding protein & B6259_RS03345 & 30 & 501 & 22 & 37 & 1.15 & $7.65^{b}$ \\
\hline $\mathrm{ABC}$ transporter substrate-binding protein & B6259_RS07820 & 372 & 1913 & 451 & 344 & 0.73 & $4.63^{b}$ \\
\hline sugar $\mathrm{ABC}$ transporter substrate-binding protein & B6259_RS02005 & 30 & 93 & 29 & 48 & 0.92 & $2.29^{b}$ \\
\hline peptide $\mathrm{ABC}$ transporter substrate-binding protein & B6259_RS08515 & 53 & 78 & 98 & 369 & $0.48^{\mathrm{c}}$ & $0.28^{\mathrm{c}}$ \\
\hline peptide $\mathrm{ABC}$ transporter substrate-binding protein & B6259_RS02685 & 1385 & 819 & 1442 & 2222 & 0.85 & $0.50^{c}$ \\
\hline $\mathrm{ABC}$ transporter ATP-binding protein & B6259_RS02660 & 238 & 119 & 369 & 320 & 0.58 & $0.45^{c}$ \\
\hline $\mathrm{ABC}$ transporter ATP-binding protein & B6259_RS07940 & 190 & 58 & 259 & 166 & 0.66 & $0.42^{c}$ \\
\hline PTS fructose transporter subunit IIC & B6259_RS00095 & 372 & 2117 & 1273 & 485 & $0.37^{\mathrm{c}}$ & $3.87^{b}$ \\
\hline PTS glucose transporter subunit IIA & B6259_RS09280 & 484 & 260 & 1200 & 517 & $0.37^{\mathrm{c}}$ & 0.62 \\
\hline PTS $\beta$-glucoside transporter subunit IIABC & B6259_RS01415 & 81 & 760 & 134 & 141 & 0.54 & $4.70^{b}$ \\
\hline PTS mannitol transporter subunit IICBA & B6259_RS00370 & 29 & 89 & 19 & 44 & 1.26 & $2.34^{b}$ \\
\hline ferrous iron transport protein $B$ & B6259_RS03880 & 471 & 389 & 531 & 150 & 0.81 & $2.72^{b}$ \\
\hline
\end{tabular}

${ }^{a}$ Data presented as mean of independent triplicates

${ }^{\mathrm{b}}$ Significantly upregulated $(\mathrm{FC} \geq 2.0, p<0.05)$

${ }^{\mathrm{c}}$ Significantly downregulated $(\mathrm{FC} \leq 0.5, p<0.05)$

transfer flavoprotein complex (Bcd/Etf complex) and butyryl-CoA: acetate CoA transferase (CoAT) [7, 16]. In the present study, genes encoding AtoB (B6259_RS06365), Crt (B6259_RS06360) and Hbd (B6259_RS06355) maintained at very high expression levels $($ TPM $>3000)$ in the lactate-supplemented cells, and were upregulated by 3.5-8.6 folds $(p<0.05)$ compared with control cells without lactate. Bcd (B6259_RS01790) was expressed at a very high level in the lactate-supplemented cells and control cells throughout the growth and stationary phases, but there was no difference between two groups. EtfAB (alpha unit, B6259_RS01785 and beta unit, B6259_RS01780) showed the Bcd-like expression profile. Another Bcd (B6259_RS02600) was expressed at relatively low level at the growth phase, but its expression was upregulated 4.5 -fold $(p<0.05)$ at the stationary phase. One CoAT gene 
(B6259_RS06345) showed high expression level in the two cultures (TPM $>150$ ), and it was markedly upregulated by 4 -fold $(p<0.05)$ in the lactate-supplemented cells than in the control at the stationary phase.

Additionally, the gene encoding phosphate acetyltransferase (Pta, B6259_RS07830) was remarkably upregulated $(p<0.05)$ at the two phases with the addition of lactate (Table 3$)$. The expression of acetate kinase (Ack, B6259_RS03430) showed no change $(p<0.05)$ in response to the addition of lactate. The two genes can produce acetate from acetyl-CoA (sourced from glycolysis or lactate oxidation), contributing to a dynamic equilibrium of acetate in cultures to some extent. By including the production of $\mathrm{H}_{2}$ and $\mathrm{CO}_{2}$ into the loop, it could provide a whole picture for carbon balance for the substrate utilization and cell biomass production. Unfortunately, the production of $\mathrm{H}_{2}$ and $\mathrm{CO}_{2}$ was not monitored in this study. In the future studies, this should be taken into consideration for improvement.

Expression of Putative ABC Transporter and Sporulation Genes

As shown in Table 3 and Fig. 5, sporulation genes showed similar expression patterns in the lactatesupplemented cells and control cells, e.g., spo0, spoIIID, spoVAE, and spoYtff, were induced to high expression at the growth and stationary phases, while spoIID, spoIIIAD, spoIVA, spoVAC, and spoVAD were expressed at low or moderate levels.

Notably, most genes for $\mathrm{ABC}$ transporter and substrate-binding protein (SBP) were no significant changes ( $p>$ 0.05) in the two groups at growth phase, except two ABC transporter genes (B6259_RS00445, B6259_RS00450), and one SBP gene (B6259_RS00440) which were upregulated by more than 2 -fold $(p<0.05$, Table 3 ) with the addition of lactate. However, many of these genes were markedly upregulated at the stationary phase $(p<0.05)$. Specially, B6259_RS07905,_RS07910,_RS00320,_RS00325 and B6259_RS07915 were increased over 10-fold $(p<0.05)$ in the lactate-supplemented cells compared with control cells.

In addition, four phosphotransferase system (PTS) transporter genes, including PTS fructose transporter subunit IIC (B6259_RS00095), PTS glucose transporter subunit IIA (B6259_RS09280), PTS $\beta$-glucoside transporter subunit IIABC (B6259_RS01415), and PTS mannitol transporter subunit IICBA (B6259_RS00370), were detected in the transcriptome of strain CPB6. Genes encoding PTS fructose and glucose transporters were expressed at high levels under both groups, but the two genes were significantly downregulated $(p<0.05)$ in the lactate-supplemented cells than in control cells at the growth phase, indicating that the two PTS transporters are sensitive to lactate supplementation. Moreover, the three PTS transporter genes (B6259_RS0095, RS01415 and RS00370) and one ferrous iron transporter gene (B6259_RS03880) were upregulated by 2- to 4-fold at stationary phase $(p<0.05$, Table 3$)$.

\section{RT-qPCR Verification}

The fold-changes in expression of 5 genes (Pfor, AtoB, $\mathrm{Hbd}, \mathrm{Crt}$, and CoAT) were measured by RT-qPCR with $16 \mathrm{~S}$ rRNA as reference gene. The five genes were significantly upregulated in the lactate-supplemented cells compared with control cells (Fig. S5). The RT-qPCR data mainly matched the RNA-Seq of 5 selected genes based FC values, which indicated that our RNA-Seq result is accurate and the conclusion from RNA-Seq should be reliable.

\section{Discussion}

Lactate is a major end-product of glycolysis or energy substrate for many anaerobic bacteria such as Acetobacterium woodii, C. botulinum and Desulfotomaculum reducens [26, 27]. The recent studies show that lactate as electron donor can be transformed into CA in either mixed anaerobes $[3,12,13]$, or in the pure anaerobic bacterium [14], but the biochemistry of lactate oxidation to CA and underlying regulatory mechanisms are still obscure. Lactate dehydrogenase (LDH) is the key enzyme in lactate production from pyruvate. LDH catalyzes the reaction converts pyruvate to lactate or the reverse reaction that converts lactate to pyruvate coupled to NADH/ $\mathrm{NAD}^{+}$redox [28]. Generally, bacteria that grow on lactate as sole energy and carbon source have a serious energetic problem because of the high redox potential of the pyruvate/lactate pair. Recently, a novel mode of lactate metabolism is proposed for strictly anaerobic bacteria [27], in which the LDH/ Etf complex uses flavinbased electron confurcation to drive endergonic lactate oxidation with $\mathrm{NAD}^{+}$as oxidant at the expense of simultaneous exergonic electron flow from reduced ferredoxin. And that, the lactate metabolism in these strictly anaerobic bacteria is negatively regulated by the transcriptional regulator [29]. In this study, the upregulation of LDHs was not observed with the addition of lactate, indicating that lactate supplementation does not trigger increased expression of LDH. Moreover, the L-ldh (B6259_RS09845) heterologously expressed in Escherichia coli BL21 (DE3) exhibits high LDH activity of driving endergonic lactate oxidation in the absence of $\mathrm{Fd}^{2-}$, and LDH oxidative activity predominates over reductive activity [30]. These results indicate that the lactate metabolism in strain CPB6 is different from other strict anaerobes. It warrants further investigation concerning the detailed regulatory mechanism of lactate oxidation in strain CPB6.

The bioproduction of $\mathrm{CA}$ is a well-known chain elongation process from acetate $(\mathrm{C} 2)$ to butyrate $(\mathrm{C} 4)$, and then to caproate (C6) via the reverse $\beta$-oxidation pathway [6]. The conversion of $\mathrm{C} 2$ to $\mathrm{C} 4$ is well understood, but little is known about the key enzymes responsible for caproyl-CoA or CA synthesis. Enzymes (e.g., AtoB, Crt, Hbd, $\mathrm{Bcd} / \mathrm{EtfAB}$ complex and CoAT) responsible for butyrate synthesis via the reverse $\beta$-oxidation are assumed to have the function in the formation of caproyl-CoA and CA [7]. However, C. tyrobutyricum, which contains these genes, only produce butyric acid instead of CA [31], while C. kluyveri and strain CPB6, which contain these genes, can further elongate $\mathrm{C} 4$ to $\mathrm{C} 6[7,15]$. It indicates that there are differences in structure and function between these genes from different organisms. In this study, the three genes (AtoB, Crt, $\mathrm{Hbd}$ ) responsible for the conversion of 
acetyl-CoA to crotonyl-CoA were markedly upregulated $(p<0.05)$ throughout the exponential and stationary phases with the addition of lactate. However, the Bcd (B6259_RS02600) and CoAT (B6259_RS06345) genes were only significantly upregulated at the stationary phase. Provided that the rate of CA accumulation was significantly higher during the stationary phase than the growth phase, the two genes are likely involved in the formation of caproyl-CoA and CA, The CoAT is the key enzyme responsible for the last step of the butyrate formation [31]. Theoretically, high-level expression of the CoAT gene should result in the accumulation of butyric acid, but significant accumulation of CA instead of butyric acid was observed in the lactate-supplemented cultures, suggesting that the CoAT prefers to convert caproyl-CoA to caproate than butyryl-CoA to butyrate. This speculate was verified by expression of the CoAT (B6259_RS06345) in E. coli BL21 (DE3). This CoAT protein could catalyze the conversion of both butyryl-CoA to butyrate and caproyl-CoA to caproate, but its catalytic efficiency with caproyl-CoA as the substrate was 3.8 times higher than that with butyryl-CoA [32]. Thus, the CoAT is a key gene that determines whether the final product is butyric acid or caproic acid.

Some bacteria develop into highly resistant spores to protect their genome and cell from certain doom when living conditions become intolerable [33]. It ensures bacterial survival under adverse environmental conditions. Sporulation in Clostridium spp. is ordinarily not triggered by starvation but by cessation of growth in the presence of excess carbon source or exposure to oxygen [33]. The two most critical factors involved in the shift to solventogenesis, a decrease in external $\mathrm{pH}$ and accumulation of acidic fermentation products, are generally assumed to be associated with the initiation of sporulation in Clostridium spp., to some extent [34]. Recent studies show that the sporulation events are uncoupled from the induction of solventogenesis in C. beijerinckii [35]. In this study, the sporulation genes showed no significant difference between the lactate supplemented cells and control cells, indicating that the sporulation events are not associated with the production of CA in strain CPB6 until the stationary phase. This may be because low concentrations of CA $(1,717 \mathrm{mg} / \mathrm{l})$ are not sufficient to initiate sporulation for strain CPB6.

$\mathrm{ABC}$ transporters are ubiquitous membrane proteins that couple the transport of diverse substrates across cellular membranes to the hydrolysis of ATP [36]. ABC transporters are generally divided into importers and exporters on the basis of the polarity of solute movement. $\mathrm{ABC}$ importers are found mostly in bacteria and are crucial in mediating the uptake of solutes including sugar, metal ions, and vitamins [37]. ABC transporters play important roles in response to lactate stress. High expression of $A B C$ transporter genes may be of benefit to organisms to maintain intercellular homeostasis under lactate stress [38] or increase intracellular ATP concentrations to protect cells against acidic damage in the initial stage of acid stress [39]. Here, nine ABC transporter genes and six SBP genes were markedly upregulated at the stationary phase. Specially, B6259_RS07905,_RS07910,_RS00320,_RS00325, and B6259_RS07915 were increased over 10-fold in the lactate supplemented cells compared to control cells, demonstrating that these genes are associated with the extrusion of CA from the cell, and the maintenance of osmotic homeostasis in cytoplasm [40].

PTS is a multiple-component carbohydrate uptake system that drives specific saccharides across the bacterial inner membrane while simultaneously catalyzing sugar phosphorylation [41]. Five distinct subfamilies of proteins related to PTS have been identified within the glucose superfamily: the lactose family, the glucose family, the $\beta$-glucoside family, the mannitol family, and the fructose family [42]. In this study, genes encoding PTS fructose, $\beta$-glucoside, and mannitol transporters were all strikingly upregulated in the lactate-supplemented cells than in control cells at the stationary phase, suggesting that these transporters may be involved in the extrusion of intracellular CA in strain CPB6, similar to the role of ABC transporters [43].

In sum, this study showed that lactate supplementation induced earlier CA production, higher CA titer, and productivity. The gene transcriptional profiles based on RNA-Seq demonstrated that supplemented lactate promoted CA production by altering the expression patterns of genes responsible for crucial metabolic pathways. Specifically, 5 genes (AtoB, Hbd, Crt, Bcd/EtfAB, and CoAT) involved in the reverse $\beta$-oxidation pathway, 11 genes encoding ABC transporter, 6 SBP genes, and 4 PTS transporter genes showed high correlation with utilization of lactate and CA production. The findings presented herein provide unique insights into the metabolic effects of lactate on CA production at the gene regulation level.

\section{Acknowledgments}

This work was supported by the Natural Science Foundation of China (31770090), Sichuan Science and Technology Support Program (2021YJ0022), and the Open-foundation project of CAS Key Laboratory of Environmental and Applied Microbiology (KLCAS-2017-01).

\section{Conflict of Interest}

The authors have no financial conflicts of interest to declare.

\section{References}

1. Brodowski F, Duber A, Zagrodnik R, Oleskowicz-Popiel P. 2020. Co-production of hydrogen and caproate for an effective bioprocessing of waste. Bioresour. Technol. 318: 123895.

2. Roghair M, Liu Y, Adiatma JC, Weusthuis RA, Bruins ME, Buisman CJN, et al. 2018. Effect of n-Caproate concentration on chain elongation and competing processes. ACS Sustain Chem. Eng. 6: 7499-7506.

3. Nzeteu CO, Trego AC, Abram F, O'Flaherty V. 2018. Reproducible, high-yielding, biological caproate production from food waste using a single-phase anaerobic reactor system. Biotechnol. Biofuels 11: 108.

4. Roghair M, Liu Y, Strik D, Weusthuis RA, Bruins ME, Buisman CJN. 2018. Development of an effective chain elongation process from acidified food waste and ethanol into n-Caproate. Front. Bioeng. Biotechnol. 6: 50. 
5. Yang PX, Leng L, Tan GYA, Dong CY, Leu SY, Chen WH, et al. 2018. Upgrading lignocellulosic ethanol for caproate production via chain elongation fermentation. Int. Biodeter. Biodegr. 135: 103-109.

6. Spirito CM, Richter H, Rabaey K, Stams AJ, Angenent LT. 2014. Chain elongation in anaerobic reactor microbiomes to recover resources from waste. Curr. Opin. Biotechnol. 27: 115-122.

7. Seedorf H, Fricke WF, Veith B, Bruggemann H, Liesegang H, Strittimatter A, et al. 2008. The genome of Clostridium kluyveri, a strict anaerobe with unique metabolic features. Proc. Natl. Acad. Sci. USA 105: 2128-2133.

8. Steinbusch KJJ, Hamelers HVM, Plugge CM, Buisman CJN. 2011. Biological formation of caproate and caprylate from acetate: fuel and chemical production from low grade biomass. Energy Environ. Sci. 4: 216-224.

9. Chen WS, Ye Y, Steinbusch KJJ, Strik DPBTB, Buisman CJN. 2016. Methanol as an alternative electron donor in chain elongation for butyrate and caproate formation. Biomass Bioenerg. 93: 201-208.

10. Kenealy WR, Waselefsky DM. 1985. Studies on the substrate range of Clostridium-Kluyveri - the use of propanol and succinate. Arch. Microbiol. 141: 187-194.

11. Jeon BS, Kim BC, Um Y, Sang BI. 2010. Production of hexanoic acid from D-galactitol by a newly isolated Clostridium sp. BS-1. Appl. Microbiol. Biotechnol. 88: 1161-1167.

12. Kucek LA, Nguyen M, Angenent LT. 2016. Conversion of l-lactate into n-caproate by a continuously fed reactor microbiome. Water Res. 93: 163-171.

13. Zhu X, Tao Y, Liang C, Li X, Wei N, Zhang W, et al. 2015. The synthesis of n-caproate from lactate: a new efficient process for medium-chain carboxylates production. Sci. Rep. 5: 14360.

14. Zhu X, Zhou Y, Wang Y, Wu T, Li X, Li D, et al. 2017. Production of high-concentration n-caproic acid from lactate through fermentation using a newly isolated Ruminococcaceae bacterium CPB6. Biotechnol. Biofuels 10: 102.

15. Wang H, Li X, Wang Y, Tao Y, Lu S, Zhu X, et al. 2018. Improvement of n-caproic acid production with Ruminococcaceae bacterium CPB6: selection of electron acceptors and carbon sources and optimization of the culture medium. Microb. Cell Fact. 17: 99.

16. Tao Y, Zhu XY, Wang H, Wang Y, Li XZ, Jin H, et al. 2017. Complete genome sequence of Ruminococcaceae bacterium CPB6: A newly isolated culture for efficient n-caproic acid production from lactate. J. Biotechnol. 259: 91-94.

17. Sedlar K, Koscova P, Vasylkivska M, Branska B, Kolek J, Kupkova K, et al. 2018. Transcription profiling of butanol producer Clostridium beijerinckii NRRL B-598 using RNA-Seq. BMC Genomics. 19: 415.

18. Zararsiz G, Goksuluk D, Korkmaz S, Eldem V, Zararsiz GE, Duru IP, et al. 2017. A comprehensive simulation study on classification of RNA-Seq data. PLoS One 12: e0182507.

19. Erlich Y, Mitra PP, delaBastide M, McCombie WR, Hannon GJ. 2008. Alta-Cyclic: a self-optimizing base caller for next-generation sequencing. Nat. Methods 5: 679-682.

20. Cock PJ, Fields CJ, Goto N, Heuer ML, Rice PM. 2010. The sanger FASTQ file format for sequences with quality scores, and the Solexa/Illumina FASTQ variants. Nucleic Acids Res. 38: 1767-1771.

21. Langmead B, Salzberg SL. 2012. Fast gapped-read alignment with Bowtie 2. Nat. Methods 9: 357-359.

22. Patro R, Mount SM, Kingsford C. 2014. Sailfish enables alignment-free isoform quantification from RNA-seq reads using lightweight algorithms. Nat. Biotechnol. 32: 462-U174.

23. Kirk DG, Palonen E, Korkeala H, Lindstrom M. 2014. Evaluation of normalization reference genes for RT-qPCR analysis of spo0A and four sporulation sigma factor genes in Clostridium botulinum Group I strain ATCC 3502. Anaerobe 26: 14-19.

24. Love MI, Huber W, Anders S. 2014. Moderated estimation of fold change and dispersion for RNA-seq data with DESeq2. Genome Biol. 15: 550 .

25. Riederer A, Takasuka TE, Makino S, Stevenson DM, Bukhman YV, Elsen NL, et al. 2011. Global gene expression patterns in Clostridium thermocellum as determined by microarray analysis of chemostat cultures on cellulose or cellobiose. Appl. Environ. Microbiol. 77: 1243-1253.

26. Rogatzki MJ, Ferguson BS, Goodwin ML, Gladden LB. 2015. Lactate is always the end product of glycolysis. Front. Neurosci. 9: 22.

27. Weghoff MC, Bertsch J, Muller V. 2015. A novel mode of lactate metabolism in strictly anaerobic bacteria. Environ. Microbiol. 17: 670-677.

28. Skory CD. 2000. Isolation and expression of lactate dehydrogenase genes from Rhizopus oryzae. Appl. Environ. Microbiol. 66: $2343-2348$.

29. Schoelmerich MC, Katsyv A, Sung W, Mijic V, Wiechmann A, Kottenhahn P, et al. 2018. Regulation of lactate metabolism in the acetogenic bacterium Acetobacterium woodii. Environ. Microbiol. 20: 4587-4595.

30. Yang Q, Wei C, Guo S, Liu J, Tao Y. 2020. Cloning and characterization of a L-lactate dehydrogenase gene from Ruminococcaceae bacterium CPB6. World J. Microbiol. Biotechnol. 36: 182

31. Lee J, Jang YS, Han MJ, Kim JY, Lee SY. 2016. Deciphering Clostridium tyrobutyricum Metabolism based on the whole-genome sequence and proteome analyses. mBio 7: e00743-16.

32. Yang Q, Guo S, Lu Q, Tao Y, Zheng D, Zhou Q, et al. 2021. Butyryl/Caproyl-CoA:Acetate CoA-transferase: cloning, expression and characterization of the key enzyme involved in medium-chain fatty acid biosynthesis. Biosci. Rep. 41: BSR20211135.

33. Sauer U, Santangelo JD, Treuner A, Buchholz M, Durre P. 1995. Sigma factor and sporulation genes in Clostridium. FEMS Microbiol. Rev. 17: 331-340.

34. Woods DR, Jones DT. 1986. Physiological responses of Bacteroides and Clostridium strains to environmental stress factors. Adv. Microb. Physiol. 28: 1-64.

35. Wang Y, Li XZ, Blaschek HP. 2013. Effects of supplementary butyrate on butanol production and the metabolic switch in Clostridium beijerinckii NCIMB 8052: genome-wide transcriptional analysis with RNA-Seq. Biotechnol. Biofuels 6: 138.

36. Hollenstein K, Dawson RJ, Locher KP. 2007. Structure and mechanism of ABC transporter proteins. Curr. Opin. Struct. Biol. 17: 412-418.

37. Cui J, Davidson AL. 2011. ABC solute importers in bacteria. Essays Biochem. 50: 85-99.

38. Qin J, Wang X, Wang L, Zhu B, Zhang X, Yao Q, et al. 2015. Comparative transcriptome analysis reveals different molecular mechanisms of Bacillus coagulans 2-6 response to sodium lactate and calcium lactate during lactic acid production. PLoS One 10: $\mathrm{e} 0124316$.

39. Zhu Z, Yang J, Yang P, Wu Z, Zhang J, Du G. 2019. Enhanced acid-stress tolerance in Lactococcus lactis NZ9000 by overexpression of ABC transporters. Microb. Cell Fact. 18: 136.

40. Jones PM, George AM. 2004. The ABC transporter structure and mechanism: perspectives on recent research. Cell Mol. Life Sci. 61: 682-699.

41. Jason G. McCoy, Elena J. Levin, Zhou M. 2015. Structural insight into the PTS sugar transporter EIIC. Biochim. Biophys. Acta 1850: $577-585$.

42. Nguyen TX, Yen MR, Barabote RD, Saier MH, Jr. 2006. Topological predictions for integral membrane permeases of the phosphoenolpyruvate:sugar phosphotransferase system. J. Mol. Microbiol. Biotechnol. 11:345-360.

43. Nikaido H, Hall JA. 1998. Overview of bacterial ABC transporters. Methods Enzymol. 292: 3-20. 